\title{
Posterior transpetrosal approach to aneurysms of the basilar trunk and vertebrobasilar junction
}

\section{Volker Seifert, M.D., Ph.D., and Dietmar Stolke, M.D., Ph.D.}

Neurosurgical Clinic, University of Essen, Essen, Germany

Aneurysms of the basilar trunk and vertebrobasilar junction represent an exceptional challenge to the neurosurgeon. Surgical access to these deep and confined lesions is hampered by the direct proximity of highly vulnerable neural structures such as the brainstem and cranial nerves, as well as by the structure of the petrous bone, which blocks direct surgical approach to these aneurysms. A number of surgical tactics consisting of different supra- and infratentorial approaches have been applied over the years to gain access to these treacherous lesions. Only recently have lateral approaches, such as the anterior transpetrosal, the retrolabyrinthine-transsigmoidal, and the combined supra/infratentorial-posterior transpetrosal approaches, directed through parts of the petrous bone, been reported for surgery of basilar trunk and vertebrobasilar junction aneurysms. Because detailed reports of direct operative intervention using the transpetrosal route for these rare and difficult lesions are scarce, the authors present their surgical experiences in nine patients with basilar trunk and vertebrobasilar junction aneurysms, in whom they operated via the supra/infratentorial-posterior transpetrosal approach. In eight patients, including one with a giant partially thrombosed basilar trunk aneurysm, direct clipping of the aneurysm via the transpetrosal route was possible. In one patient with a giant vertebrobasilar junction aneurysm, the completely calcified aneurysm sac was resected after occlusion of the vertebral artery. In total, one patient died and another experienced postoperative accentuation of preexisting cranial nerve deficits. Two patients had transient cerebrospinal fluid leakage, and the postoperative course was uneventful in the remaining seven. Postoperative angiography demonstrated complete aneurysm clipping in eight patients and relief of preoperative brainstem compression in the patient with the giant vertebrobasilar junction aneurysm. It is concluded that the supra/infratentorial-posterior transpetrosal approach allows excellent access to the basilar artery trunk and vertebrobasilar junction and can be considered the approach of choice to selected aneurysms located in this area.

Key Words * vertebrobasilar aneurysm * subarachnoid hemorrhage * skull base approach * transpetrosal approach

Aneurysms of the basilar trunk and vertebrobasilar junction represent a surgical challenge because of the direct proximity of highly vulnerable neural structures such as the brainstem and cranial nerves. A direct approach to these aneurysms is often blocked by the petrous bone. A number of approaches have been attempted over the years to gain access to these lesions; among these are: the pterional,[35] subtemporal,[4,21,24,33] suboccipital-retromastoidal,[30,33] far-lateral,[10,22,29] and 
transoral-transclival.[2,3,11,35] Only recently have lateral approaches, such as the anterior transpetrosal,[26] the retrolabyrinthine-transsigmoidal,[6] and the combined supra/infratentorial-posterior transpetrosal approaches,[17,22,29,32] directed through parts of the petrous bone, been reported for surgery of basilar trunk and vertebrobasilar junction aneurysms. We present our experience in nine patients with basilar trunk and vertebrobasilar junction aneurysms in whom we operated via the supra/infratentorial-posterior transpetrosal approach.

\section{CLINICAL MATERIAL AND METHODS}

Over a period of 6.5 years, nine patients harboring aneurysms of the lower basilar trunk and vertebrobasilar junction underwent operation performed by one surgeon (V.S.) via a supra/infratentorial-posterior transpetrosal approach. This series consists of six men and three women ranging in age from 36 to 65 years, in whom three aneurysms were located in the area of the vertebrobasilar junction, one of these was calcified and giant in size; two aneurysms were located at the vertebral artery below the vertebrobasilar junction; and four in the lower basilar trunk, including one giant aneurysm. Five of these nine patients presented with typical clinical signs of subarachnoid hemorrhage (SAH) from their vertebrobasilar aneurysm. All five patients were referred to our institution soon after discovery of their aneurysm. Clinical grade on admission was Hunt and Hess[14] Grade II in one patient, Grade III in three patients, and Grade IV in one patient. Four patients had delayed surgery 7 to 21 days after SAH. One patient who suffered two recurrent hemorrhages within 12 hours after his initial SAH underwent early surgery. Two patients with giant aneurysms of the basilar trunk and vertebrobasilar junction, respectively, presented with signs of progressive brainstem compression and cranial nerve dysfunction. One patient underwent surgery for a large vertebral aneurysm, which was initially diagnosed incidentally on magnetic resonance (MR) imaging, and in one patient an asymptomatic vertebrobasilar junction aneurysm was identified during the course of angiography, initiated because of SAH from an internal carotid artery aneurysm. Direct clipping of the aneurysm via the transpetrosal approach was possible in eight patients, including the one with a giant basilar trunk aneurysm. In the patient with a giant vertebrobasilar junction aneurysm, the completely calcified aneurysm sac was resected after occlusion of the vertebral artery. The one patient undergoing early surgery, who was classified as a Grade IV, died after multiple recurrent hemorrhages. Transient postoperative accentuation of preexisting cranial nerve deficits occurred in another patient. Except transient cerebrospinal fluid leakage in two patients, which stopped after temporary lumbar drainage, the postoperative course was uneventful in the remaining seven patients. Postoperative angiography demonstrated complete aneurysm clipping in eight patients and relief of preoperative brainstem compression in the patient with the giant vertebrobasilar junction aneurysm.

\section{SURGICAL TECHNIQUE}



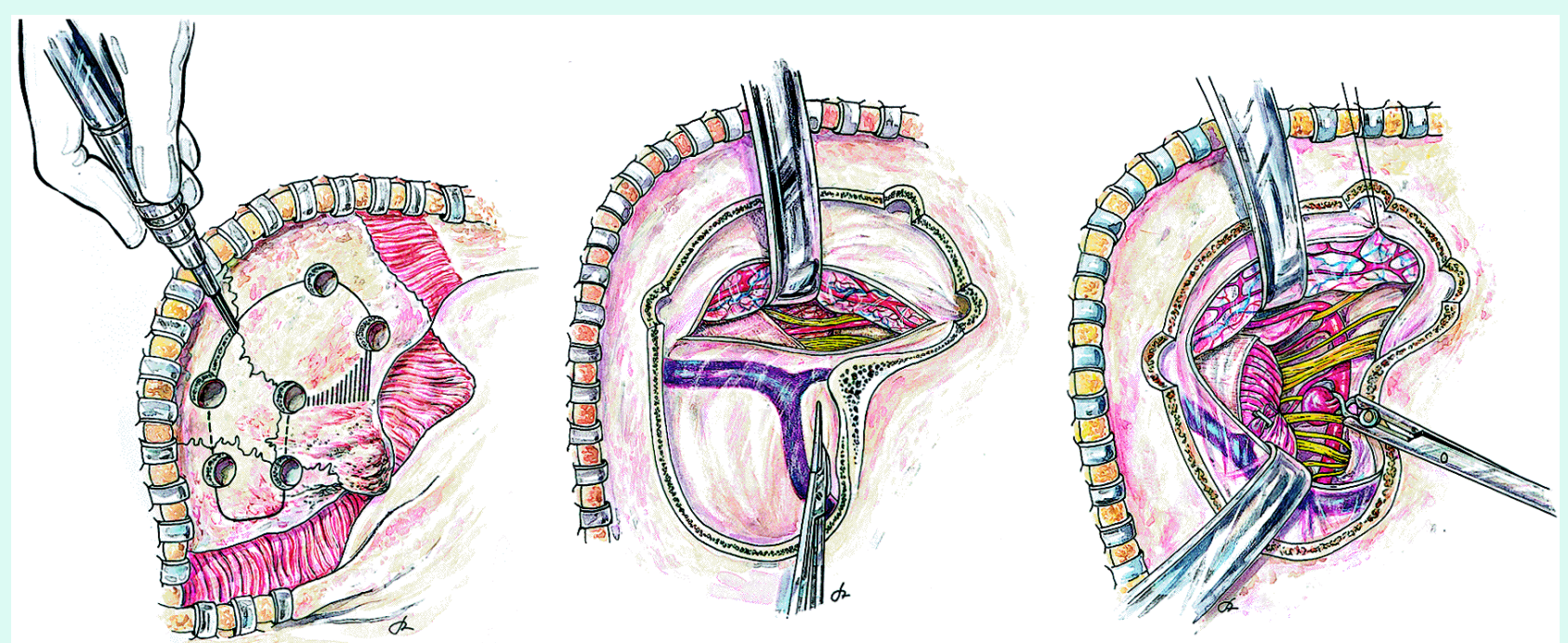

Fig. 1. Left: Intraoperative sketch showing the combined supra/infratentorial trepanation for the posterior transpetrosal approach. Supra- and infratentorial burr holes are connected by a craniotome. Burr holes bordering the transverse sinus are then connected using a high-speed drill. The shaded area is removed by rongeur and high-speed drill down to the level of the posterior temporal fossa. Center: After completion of combined supra/infratentorial trepanation, radical removal of the posterior petrous bone is accomplished with preservation of labyrinthine structures and exposure of the presigmoidal dura in Trautmann's triangle. The temporal fossa dura is incised parallel to the transverse sinus and basal temporal fossa. The posterior temporal lobe is slightly elevated, and the anterolateral tentorium is partially revealed. The presigmoidal dura covering the posterior fossa is incised. The superior petrosal sinus is ligated, and the tentorium is completely transected. Right: Intraoperative sketch illustrating transpetrosal clipping of a large lower basilar trunk aneurysm. Transsection of superior petrosal sinus and tentorium allows retraction of sigmoid sinus and tangential exposure of the vertebrobasilar junction and basilar artery.

All patients in this series underwent surgery in the semisitting "lounging" position; it is the standard position used for all procedures in the posterior fossa performed in our clinic and is also routinely used for all petroclival lesions operated on via the combined transpetrosal approach. Electrophysiological monitoring using brainstem auditory and somatosensory evoked potentials is performed routinely throughout these procedures. An L-shaped incision is used, starting in the temporal region slightly above the ear, curving posteriorly, and finishing parallel and slightly below the mastoid process. The temporal and suboccipital musculature is incised and retracted together with the scalp using fishhooks and self-retaining retractors, so as to expose the temporobasal and lateral suboccipital skull as well as the complete mastoid process. A combined supra/infratentorial craniotomy is performed (Fig. 1 left). After the bone flap has been elevated, complete unroofing of the sigmoid sinus is accomplished with the aid of a high-speed drill and a surgical microscope. This is followed by a radical posterior petrosectomy to gain sufficient exposure of the presigmoid dura from the superior petrosal sinus to the level of the jugular bulb. During this procedure, great care must be taken to preserve the integrity of the semicircular canals, especially the posterior semicircular canal, which has the highest risk of being injured during the extensive drilling of the posterior petrous bone. If a semicircular canal is inadvertently opened, it must be sealed immediately with bone wax. Upon completing the extradural bone work, the temporal dura is incised parallel to the transverse sinus and the floor of the temporal fossa; after which, the presigmoid dura in Trautmann's triangle, which covers the posterior fossa, is incised up to the superior petrosal sinus, 
which is ligated using small hemoclips and cut (Fig. 1 center). The temporal lobe is slightly elevated and the tentorium is transected. Sectioning of the tentorium is performed parallel to the petrous bone in the direction of the trochlear nerve, which can be seen in the depth of the operating field covering its arachnoid sheath and coursing in front of the anterior margin of the tentorium. The vein of Labbe must be preserved during elevation of the temporal lobe and during cutting of the tentorium. After the tentorium has been cut completely, the sigmoid sinus and the remaining portion of the tentorium are retracted by a self-retaining retractor, exposing the clival and juxtaclival region along with the basilar artery from the upper basilar region down to the level of the vertebrobasilar junction and ipsilateral vertebral artery. After proximal and distal control of the aneurysm-bearing vessel has been achieved, the origin of the aneurysm is dissected and clipped using a standard aneurysm clip.(Fig. 1 right) After inspection of the area adjacent to the aneurysm clip has confirmed patency of perforating vessels, watertight closure of the dura is achieved using a fascial and muscular graft augmented by fibrin glue. The bone flap is repositioned and secured with titanium microplates. The craniectomy defect is filled with a pedicled temporalis muscle flap. However, for the last two patients we have covered this area with a titanium mesh molded according to the outer appearance of the mastoid bone and fixed it with titanium microscrews. This procedure has produced an excellent cosmetic result. A subcutaneous drain is inserted and the surgical wound is closed in layers in the typical fashion.

\section{Illustrative Cases}

\section{Case 1}

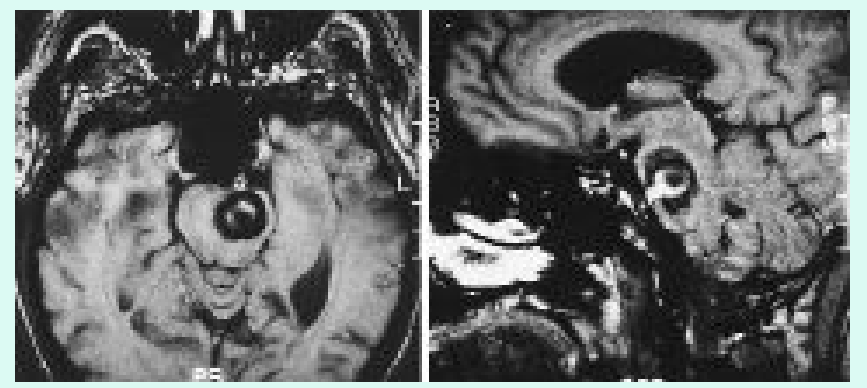

Fig. 2. Case1. Axial (left) and sagittal (right) magnetic resonance imaging showing the location of the large intrapontine lesion suspected of being a partially thrombosed giant basilar trunk aneurysm.

This 56-year-old man became symptomatic and showed rapidly progressing signs of brainstem compression consisting of intermittent periods of gait disturbance and cranial nerve dysfunction. Computerized tomography (CT) and MR imaging revealed a large intrapontine lesion that looked suspiciously like a partially thrombosed giant aneurysm of the basilar trunk (Fig. 2). Vertebral angiography demonstrated that the origin and a portion of the aneurysm fundus arising from the midportion of the basilar artery was still filled with blood, although the remaining part of the giant aneurysm sac was thrombosed (Fig. 3 left). 


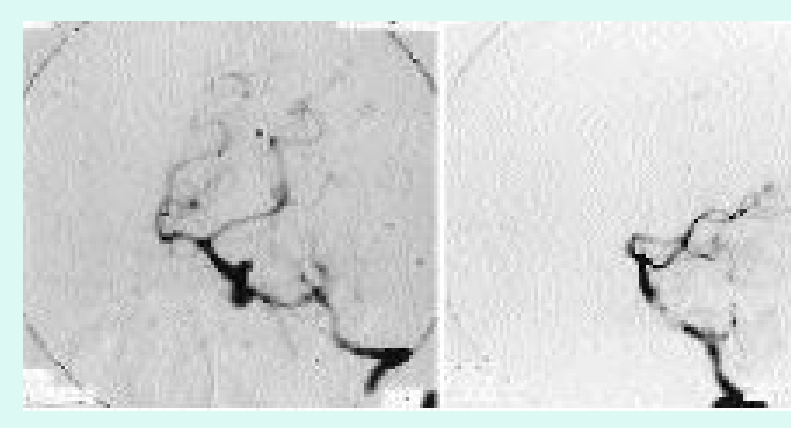

Fig. 3. Case 1. Left: Preoperative vertebral subtraction angiography confirming the diagnosis of an aneurysm originating from the midportion of the basilar artery. Only a small portion of the origin of the aneurysm is still blood filled. Clinical symptoms in the patient are due to propagated pulsations from the aneurysm base and gradual enlargement of the aneurysm sac. Right: Postoperative digital subtraction angiography confirming complete clipping of the aneurysm.

Because of progressive neurological deterioration in the patient thought to be due to propagated pulsations and gradual enlargement of the aneurysm sac through its still-patent origin, direct surgical intervention via the posterior transpetrosal approach was initiated. After sharp dissection of the cisternal arachnoid, the trochlear and trigeminal nerves were mobilized and the origin of the aneurysm was identified, slightly superior to the course of the third cranial nerve. Proximal and distal control of the basilar artery was achieved by further dissection of the basilar trunk cranial and caudal to the base of the aneurysm. Then the aneurysm was clipped with a slightly curved Yasargil clip. The postoperative course of the patient was uneventful. All preoperative signs of brainstem alteration resolved completely within a few weeks, and postoperative vertebral angiography demonstrated complete clipping of the aneurysm (Fig. 3 right). Magnetic resonance imaging 6 months postsurgery clearly revealed that the space-occupying aneurysm sac had shrunken completely after aneurysm clipping, leaving no apparent radiological or clinical signs of intrapontine mass or brainstem compression (Fig. 4).
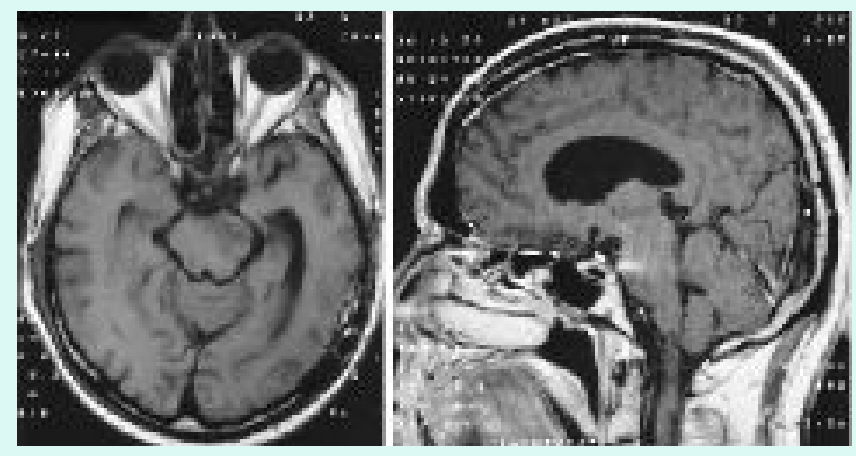

Fig. 4. Case 1. Postoperative axial (left) and sagittal (right) magnetic resonance imaging obtained 6 months postoperatively demonstrating that, despite extensive preoperative thrombosis, the giant aneurysm sac has shrunk completely without any remaining space-occupying effect within the pons.

\section{Case 2}

This 36-year-old man became symptomatic and showed rapidly progressing signs of lower cranial nerve dysfunction accompanied by dizziness and gait disturbance. The patient was already bedridden on presentation to our clinic. Computerized tomography and MR imaging revealed a large mass in the posterior fossa, originating primarily from the left vertebral artery, that resembled a giant thrombosed 
aneurysm of the vertebrobasilar junction (Fig. 5).
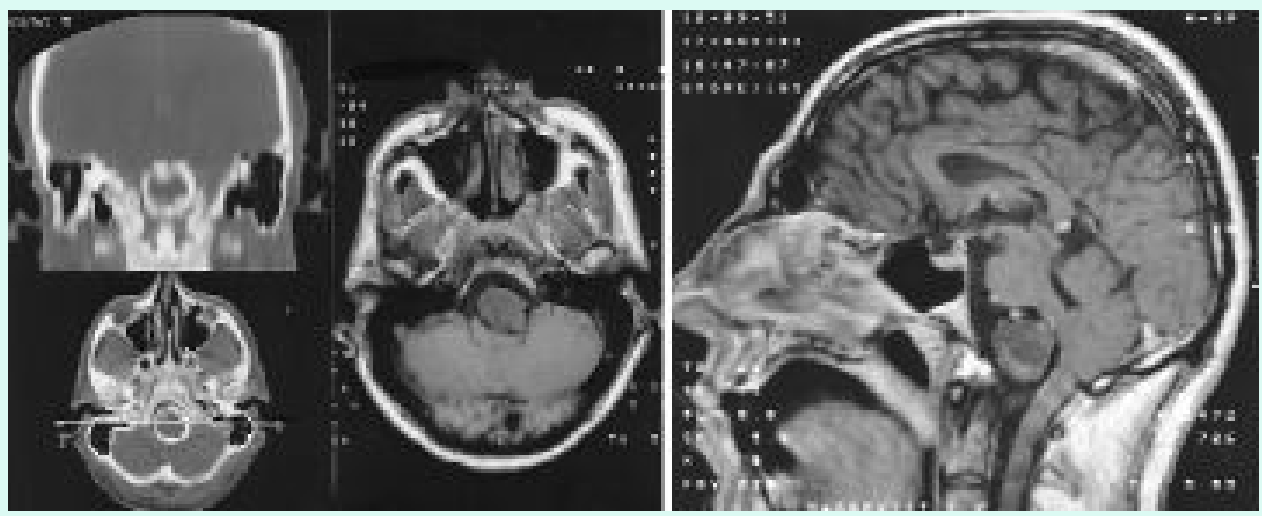

Fig. 5. Case 2. Axial computerized tomography scan with coronal reconstruction (left) showing a giant calcified vertebral artery aneurysm of the posterior fossa. Axial (center) and sagittal (right) magnetic resonance imaging showing massive anterior compression and flattening of the brainstem by the giant aneurysm.

Vertebral angiography demonstrated no filling of the aneurysm sac; however, the basilar artery was fed only by the displaced right vertebral artery (Fig. 6 left). Because of progressive deterioration in the patient, surgery was performed. The aneurysm was first explored using a left-sided far-lateral transcondylar route; inspection of the aneurysm revealed that the sac was completely calcified. Because of its size and calcification, the aneurysm sac could not be adequately mobilized by the far-lateral approach to gain sufficient access to the proximal basilar artery distal to the vertebrobasilar junction. Therefore the presigmoidal, transpetrosal, transtentorial extension of the approach was initiated to identify the basilar artery distal to the aneurysm sac and to allow for adequate control of this part of the vessel. The still-patent left-sided vertebral artery was clipped just before its entrance to the aneurysm via the far-lateral approach. A hole was drilled in the calcified wall of the aneurysm sac using a high-speed drill and the sac was completely resected by piecemeal removal. Postoperatively, the patient's lower cranial nerve deficits persisted for several weeks, until he was transferred to a rehabilitation center where he steadily improved, with almost complete regression of the deficits. Postoperative MR imaging demonstrated complete removal of the aneurysm with radiological reversal of preoperative brainstem compression (Fig. 6 right).

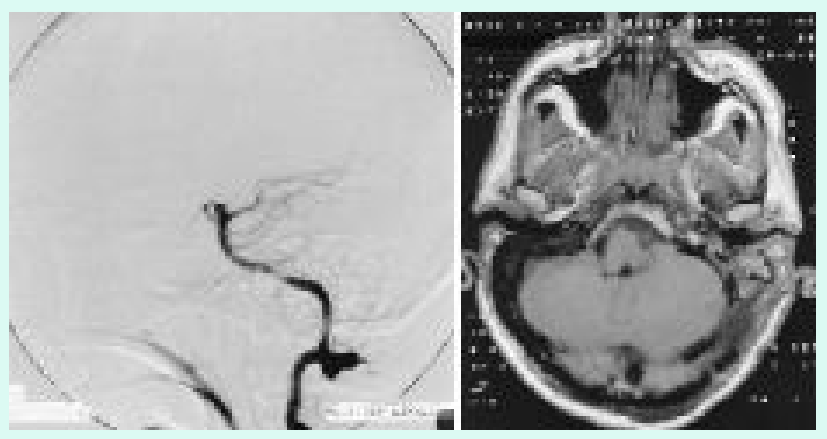

Fig. 6. Case 2. Left: Preoperative angiography demonstrating that the basilar artery fills only from the right-sided vertebral artery, which is displaced by the giant calcified aneurysm sac. Right: Postoperative magnetic resonance image, axial projection, 2 weeks after surgery demonstrating complete resection of the calcified aneurysm sac. The preoperatively compressed and flattened brainstem is already regaining almost normal configuration. 
This 37-year-old woman was admitted to our clinic after a recent SAH. She presented in Grade II Hunt and Hess condition. Cerebral panangiography revealed a large lobulated aneurysm originating from the lower basilar trunk approximately $5 \mathrm{~mm}$ above the vertebrobasilar junction (Fig. 7 left).

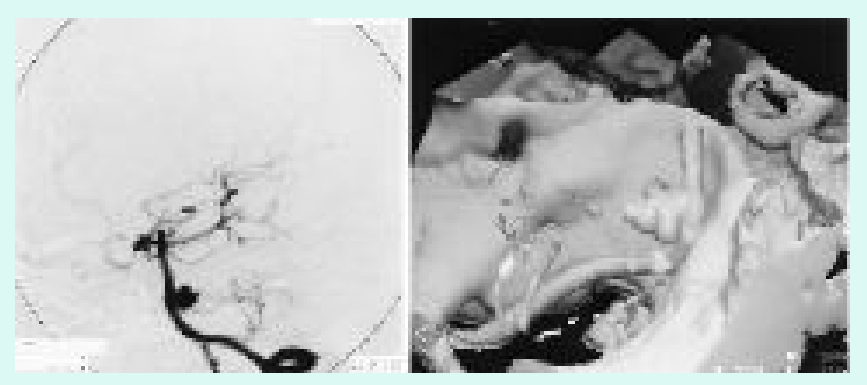

Fig. 7. Case 3. Preoperative vertebral angiography (left) showing a large lobulated aneurysm of the lower basilar trunk. Preoperative three-dimensional spiral angiography-computerized tomography image (right) demonstrating the exact anatomical location of the aneurysm, which is located slightly above the vertebrobasilar junction. Both vertebral arteries and the lower basilar artery are deviated to the right side; therefore, the aneurysm was approached via the patient's right side.

Seven days after initial SAH, spiral angiography-CT scanning with three-dimensional reconstruction of the posterior circulation was obtained. This study demonstrated the anatomical and topographical relation of the large aneurysm and the parent basilar artery (Fig. 7 right). As the lower part of the basilar artery deviated to the right side, a right-sided combined supra/infratentorial-transpetrosal approach was performed 1 day later. Transection of the tentorium and slight retraction of the sigmoid sinus revealed the aneurysm; the partially dense arachnoid adhesions were sharply dissected and the aneurysm was clipped with a long and straight clip (Fig. 8).

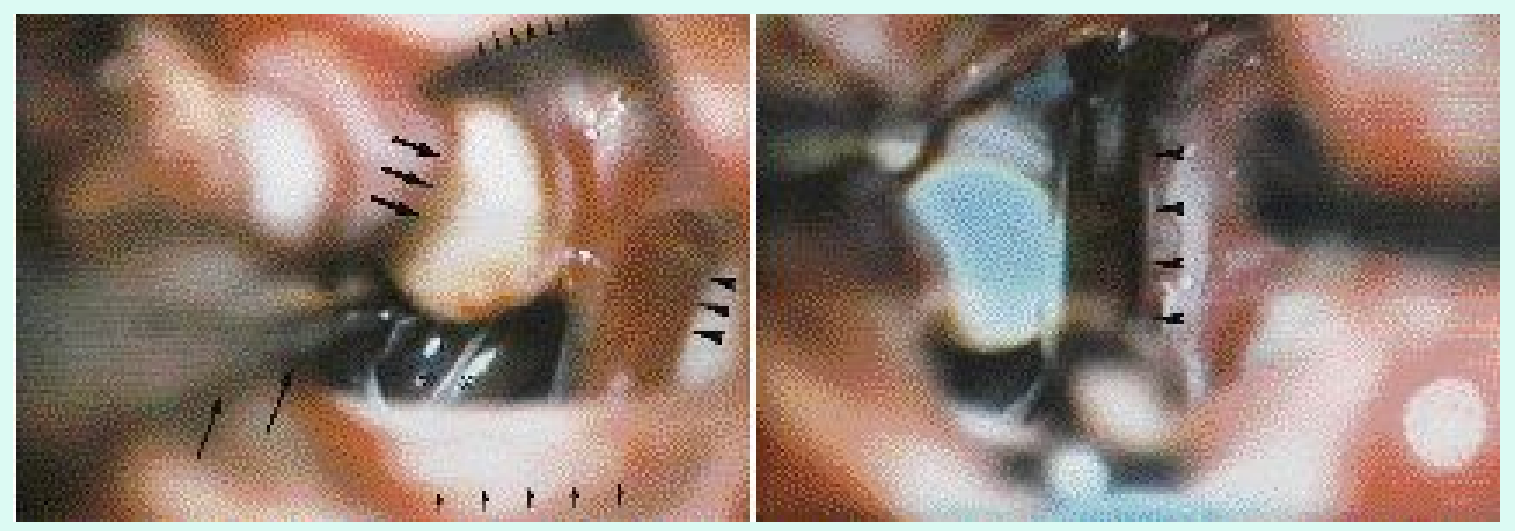

Fig. 8. Case 3. Left: Intraoperative videophotograph of the lower basilar artery (large arrowheads) and the aneurysm (large arrows) as seen from the right transpetrosal approach. The trigeminal (small arrowheads) and facial nerves (small arrows) border the tangential approach to the aneurysm. Sucker tip and arachnoid trabecular are indicated by long arrows and asterisks, respectively. Right: Intraoperative videophotograph obtained after clipping of the aneurysm. The blades of the aneurysm clip are indicated by large arrowheads.

The patient's postoperative course was uneventful apart from transient, incomplete diminished hearing on the right side. Control angiography, 2 1/2 weeks after surgery, revealed complete clipping of the aneurysm (Fig. 9). 


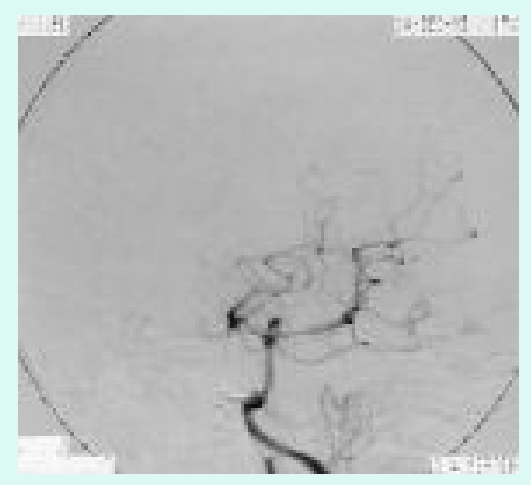

Fig. 9. Case 3. Postoperative angiography demonstrating complete clipping of the aneurysm.

\section{DISCUSSION}

Surgery of aneurysms of the basilar trunk and vertebrobasilar junction performed via routine supra- or infratentorial approaches is fraught with the difficulty of working through an extremely long and narrow tunnel bordered by bone and highly vulnerable neurovascular structures as well as the additional necessity of retracting the temporal lobe, cerebellum, and brainstem to gain access to the aneurysm.[20] The advantage of aggressive removal of portions of the posterolateral skull base such as the mastoid and petrous bone, lies in the fact that a completely flat and tangential approach to the clival and juxtaclival region (including the basilar trunk and vertebrobasilar junction) parallel to the cranial nerves may be made while almost completely avoiding retraction of neural tissue. [1,5,31,32] Advances in skull base surgery, including the ability to access deep-seated neurovascular complexes such as the basilar trunk and vertebrobasilar junction, are primarily based on the application of innovative skull base approaches. The supra/infratentorial transpetrosal approach, which has gradually developed as a combination from standard otosurgical and neurosurgical approaches, stands as an excellent example of such an innovation. [1,7,8,12,13,17-19,22,26,27] The first description of a combined supra/infratentorial approach to vertebrobasilar aneurysms was presented by Kasdon and Stein[15] in 1979 (Table 1). 
TABLE 1

RESULTS OF SURGERV US NG THE COMBNED SU PRA/INFRATENTORIAL-TRANSPETROSAL APPROACH IN 40 PATIENTS WITH BASILAR TRUNK AND VERTEBROBASILAR JUNCTION ANEURVSM ${ }^{\star}$

\begin{tabular}{|c|c|c|c|c|}
\hline Authors \& Year & $\begin{array}{l}\text { No. of } \\
\text { Patients }\end{array}$ & $\begin{array}{l}\text { Localion of } \\
\text { Aneurysm }\end{array}$ & $\begin{array}{l}\text { Variati ons in } \\
\text { Approach }\end{array}$ & Outcome \\
\hline $\begin{array}{l}\text { Kasdon \& Stein, } 1979 \\
\text { Hashi, et al.,1982 }\end{array}$ & $\begin{array}{l}2 \\
3\end{array}$ & $\begin{array}{l}\text { VA, VBJ } \\
\text { VÁ (2), VBJ }\end{array}$ & $\begin{array}{l}\text { section of transwerse sinus } \\
\text { combined supra dnfra, } \\
\text { retrolaby transpet }\end{array}$ & $\begin{array}{l}\text { good } \\
\text { good (2) } \\
\text { death (1) }\end{array}$ \\
\hline Sekhar \& Estonillo, 1986 & 2 & VÁ & $\begin{array}{l}\text { transtem, transcoch, } \\
\text { section of } s \sin 1 \text { patient }\end{array}$ & good, death \\
\hline Giannotta \& Maceri, 1988 & 3 & $\begin{array}{l}\text { BA trunk (2), } \\
\text { V'BJ }\end{array}$ & $\begin{array}{l}\text { radical mastoidectom } y_{1} \\
\text { section of } s s\end{array}$ & good \\
\hline Solomon \& Stein, 1988 & 5 & BA trunk & retrolaby, section of ss & $\begin{array}{l}\text { no detailed } \\
\text { in form ation }\end{array}$ \\
\hline Rosenberg, et al., 1992 & 3 & $\begin{array}{l}\text { BÁ trunk, } \\
\text { VBJ (2) }\end{array}$ & $\begin{array}{l}\text { retrolaby, } \\
\text { section of } s\end{array}$ & good \\
\hline Spetter, et al., 1992 & 2 & BA trunk & $\begin{array}{l}\text { com tined supradnfra, } \\
\text { retrolaby transpet }\end{array}$ & good \\
\hline King, et al., 1993 & 4 & $\begin{array}{l}\text { BA trunk (3), } \\
\text { V'B.J }\end{array}$ & $\begin{array}{l}\text { com bined supradnfra, } \\
\text { retrolaby transpet }\end{array}$ & good \\
\hline Origitano, et al., 1993 & 3 & BÁ trunk & $\begin{array}{l}\text { com bined supradnfra, } \\
\text { retrolaby transpet }\end{array}$ & fair, good \\
\hline Mizoi, et al., 1994 & 3 & BÁ trunk & $\begin{array}{l}\text { com tined supradnfra, } \\
\text { retrolaby transpet }\end{array}$ & good \\
\hline Sekhar, et al., 1994 & 2 & BÁ trunk & $\begin{array}{l}\text { retrolaby petrosal, } \\
\text { transcoch petrosal }\end{array}$ & good \\
\hline Present series, 1996 & 9 & $\begin{array}{l}\text { Bд̈ trunk (4) } \\
\text { VÄ (2) VBj' (3) }\end{array}$ & $\begin{array}{l}\text { combined supradnfra, } \\
\text { retrolaby transpet }\end{array}$ & $\begin{array}{l}\text { good (7) } \\
\text { fair (1) } \\
\text { death (1) }\end{array}$ \\
\hline
\end{tabular}

" $\mathrm{BA}=$ basilar artery, retrolaby = retrolabyrin thine; $s \mathrm{~s}=$ sigmoid sinus; supradnfra = supra.rinfratentorial; transcoch = transcochlear; transpet = transpetrosal; $\mathrm{VA}=$ vertetral artery; $\mathrm{VBJ}=$ vertebrobasilar junction. Data collected from computer-based literature search of peer-revie ned joumals.

Their approach included transection of the transverse sinus and tentorium with subsequent exposure of the vertebral artery and vertebrobasilar junction. Using this approach the authors successfully treated two patients with aneurysms of the vertebral and lower basilar artery. In 1982 Hashi and coworkers[9] reported on the first use of the transpetrosal combined supra/infratentorial approach to vertebrobasilar aneurysms. Although their route to exposure was based on the initial work presented by Kasdon and Stein, they considered the division of the transverse and sigmoid sinuses a serious drawback to the procedure, limiting it to the side of nondominant venous return. After reviewing the surgical techniques of transpetrosal exposure used by Morrisson and King[22] and Hakuba and coworkers[7,8] Hashi, et al., refrained from transection of the sigmoid sinus. Instead, after performing a posterior petrosectomy with sparing of the labyrinth and exposure of a limited area of the presigmoid dura, they divided the superior petrosal sinus, transected the tentorium, and exposed the vertebrobasilar area. Using this approach, they successfully clipped two aneurysms of the vertebral artery and one in the vertebrobasilar junction. Kawase and coworkers[16] described their experience using a transpetrosal approach for aneurysms of the lower basilar artery in two patients. However, the technique used by Kawase, et al., differs significantly from the technique described by Hashi, et al., being basically an anterior transpetrosal approach directed through the middle fossa and Kawase's triangle. Sekhar and Estonillo[28] described the surgical anatomy of the transtemporal approach to the skull base. The authors reported on the surgical treatment of vertebral artery aneurysms in two patients in the clinical section of their article which described the applicability of the transtemporal approach for exposure of vertebrobasilar aneurysms. Giannotta and Maceri[6] reported on their experience using a retrolabyrinthine transsigmoidal approach 
in three patients with vertebrobasilar aneurysms. The authors performed a radical modified mastoidectomy exposing an area bordered superiorly by the floor of the middle fossa and the superior petrosal sinus, inferiorly by the jugular bulb, and anteriorly by the posterior semicircular canal. By removing the bone over the sigmoid sinus and a few centimeters behind it, the posterior fossa dura, anterior and posterior to the sigmoid sinus, was exposed, and the sinus was divided. Using this exposure, which avoids transection of the tentorium, two aneurysms of the basilar artery trunk and one vertebrobasilar junction aneurysm were clipped successfully. In the same year, Solomon and Stein[30] summarized their experiences of approaches to aneurysms of the vertebral and basilar arteries. Among their group of 44 patients, five patients with midbasilar aneurysms were treated using a combined supra/infratentorial exposure, with transection of the sigmoid sinus and tentorium. Rosenberg and coworkers[25] reported on three patients with aneurysms of the vertebrobasilar circulation who were operated on via a retrolabyrinthine-transsigmoidal approach which was identical to the one initially described by Giannotta and Maceri. The authors were able to obliterate an aneurysm of the lower basilar trunk and an aneurysm of the vertebrobasilar junction successfully using this exposure. Spetzler, et $a l .$, [32] presented their surgical results in 46 cases of tumorous and vascular lesions of the petrous clival region, obtained using a combined supra/infratentorial approach. Among the nine vascular lesions treated, two were midbasilar artery aneurysms both of which were clipped via the retrolabyrinthine-presigmoidal variation of the combined exposure. King and coworkers[17] presented their results using the transpetrosal approach to various petroclival lesions and specifically in three patients with basilar trunk aneurysms and one patient with a vertebrobasilar junction aneurysm. In a summary of their results in the application of skull base approaches to complex cerebral aneurysms in 22 patients, Origitano, et al.,[23] reported on one patient with a giant aneurysm of the basilar trunk and another with an aneurysm located at the vertebrobasilar junction in whom surgery was performed via the transpetrosal approach. One aneurysm was successfully clipped, and the giant aneurysm was trapped. Mizoi and coworkers[21] presented their results in 5 patients with basilar trunk aneurysms, in whom temporary balloon occlusion of the basilar artery was used as an adjunct to clipping; this series included two patients operated on via a combined supra/infratentorial-transpetrosal approach. Sekhar and coworkers[29] detailed their surgical results in cranial base approaches to 38 intracranial aneurysms. Among these cases, three vertebrobasilar aneurysms were approached successfully via the transpetrosal-presigmoidal approach.

Our experience in the use of the transpetrosal route for aneurysms of basilar trunk and vertebrobasilar junction in nine patients are in agreement with data from the literature. However, the use of this approach must be considered cautiously and weighed against the application of other more routine approaches to vertebrobasilar aneurysms. All aneurysms of the upper third of the basilar trunk are relatively easily accessible by either the pterional or the subtemporal approach, and most aneurysms of the vertebral artery can be satisfactorily reached by the retrocondylar far-lateral approach; however, aneurysms of the lower basilar trunk and vertebrobasilar junction are located in a sort of "no man's land." In this region, supra- or infratentorial approaches can only be applied with considerable difficulty and risk of damage to the neighboring neurovascular structures of the brainstem and cranial nerves. We have used the combined supra/infratentorial-transpetrosal approach in more than 40 patients over a period of 8 years for a large variety of tumorous or vascular clivus-related lesions; the good exposure and almost retraction-free access to lower basilar trunk and vertebrobasilar junction aneurysms make this approach an excellent choice. With the prerequisite of adequate knowledge of the complex anatomy of the petrous bone and experience in skull base approaches, the application of this approach to surgery of selected vertebrobasilar aneurysms is straight forward, without relevant approach-related complications, and, 
following anatomical closure of the petrosectomy defect, produces an excellent cosmetic result.

\section{References}

1. Al-Mefty O, Fox JL, Smith RR: Petrosal approach for petroclival meningiomas. Neurosurgery 22:510-517, 1988

2. Archer DJ, Young S, Uttley D: Basilar aneurysms: a new transclival approach via maxillotomy. J Neurosurg 67:54-58, 1987

3. Crockard HA, Koskel T, Watkin N: Transoral transclival clipping of anterior inferior cerebellar aneurysm using new rotating applier. J Neurosurg 75:483-485, 1991

4. Drake CG: The treatment of aneurysms of the posterior circulation. Clin Neurosurg 26:96-144, 1979

5. Fukushima T: Combined supra-and infra-parapetrosal approach for petroclival lesions, in Sekhar LN, Janecka IP (eds): Surgery of Skull Base Tumors. New York: Raven Press, 1993, pp 661-670

6. Giannotta SL, Maceri DR: Retrolabyrinthine transsigmoid approach to basilar trunk and vertebrobasilar artery junction aneurysms. Technical note. J Neurosurg 69:461-466, 1988

7. Hakuba A, Nishimura S, Inoue Y: Transpetrosal-transtentorial approach and its application in the therapy of retrochiasmatic craniopharyngiomas. Surg Neurol 24:405-415, 1985

8. Hakuba A, Nishimura S, Jang BJ: A combined retroauricular and preauricular transpetrosal-transtentorial approach to clivus meningiomas. Surg Neurol 30:108-116, 1988

9. Hashi K, Nin K, Shimotake K: Transpetrosal combined supratentorial and infratentorial approach for midline vertebro-basilar aneurysms. Mod Neurosurg 1:442-448, 1982

10. Heros, RC: Lateral suboccipital approach for vertebral and vertebrobasilar artery lesions. J Neurosurg 64:559-562, 1986

11. Hitchcock E, Cowie R: Transoral-transclival clipping of a midline vertebral artery aneurysm. J Neurol Neurosurg Psychiatry 46:446-448, 1983

12. Hitselberger WE, House WF: A combined approach to the cerebellopontine angle. A suboccipital-petrosal approach. Arch Otolaryng 84:267-285, 1966

13. House WF, Hitselberger WE: The transcochlear approach to the skull base. Arch Otolaryngol 102:334-342, 1976

14. Hunt WE, Hess RM: Surgical risk as related to time of intervention in the repair of intracranial aneurysms. J Neurosurg 28:14-20, 1968

15. Kasdon DL, Stein BM: Combined supratentorial and infratentorial exposure for low-lying basilar aneurysms. Neurosurgery 4:422-426, 1979

16. Kawase T, Toya S, Shiobara R, et al: Transpetrosal approach for aneurysms of the lower basilar artery. J Neurosurg 63:857-861, 1985

17. King WA, Black KL, Martin NA, et al: The petrosal approach with hearing preservation. J 
Neurosurg 79:508-514, 1993

18. Malis LI: Surgical resection of tumors of the skull base, in Wilkins RH, Rengachary SS (eds): Neurosurgery. New York: McGraw Hill, 1985, Vol 1, pp 1011-1021

19. Malis LI: The petrosal approach. Clin Neurosurg 37:528-540, 1990

20. Miller CG, van Loveren HR, Keller JT, et al: Transpetrosal approach: surgical anatomy and technique. Neurosurgery 33: 461-469, 1993

21. Mizoi K, Yoshimoto T, Takahashi A, et al: Direct clipping of basilar trunk aneurysms using temporary balloon occlusion. J Neurosurg 80:230-236, 1994

22. Morrison AW, King TT: Experiences with a translabyrinthine-transtentorial approach to the cerebellopontine angle. Technical note. J Neurosurg 38:382-390, 1973

23. Origitano TC, Anderson DE, Tarassoli Y, et al: Skull base approaches to complex cerebral aneurysms. Surg Neurol 40:339-346, 1993

24. Peerless SJ, Drake CG: Management of aneurysms of posterior circulation, in Youmans JR (ed): Neurological Surgery. A Comprehensive Guide to the Diagnosis and Management of Neurosurgical Problems. Philadelphia: WB Saunders,1982, Vol 3, pp 1715-1763

25. Rosenberg SI, Flamm ES, Hoffer ME, et al: The retrolabyrinthine transsigmoid approach to midbasilar artery aneurysms. Laryngoscope 102:100-104, 1992

26. Samii M, Ammirati M: The combined supra-infratentorial pre-sigmoid sinus avenue to the petro-clival region. Surgical technique and clinical applications. Acta Neurochir 95:6-12, 1988

27. Samii M, Ammirati M, Mahran A, et al: Surgery of petroclival meningiomas: report of 24 cases. Neurosurgery 24:12-17, 1989

28. Sekhar LN, Estonillo R: Transtemporal approach to the skull base: an anatomical study.

Neurosurgery 19:799-808, 1986

29. Sekhar LN, Kalia KK, Yonas H, et al: Cranial base approaches to intracranial aneurysms in the subarachnoid space. Neurosurgery 35:472-483, 1994

30. Solomon RA, Stein BM: Surgical approaches to aneurysms of the vertebral and basilar arteries. Neurosurgery 23:203-208, 1988

31. Spetzler RF, Daspit CP, Pappas CTE: Combined approach for lesions involving the cerebellopontine angle and skull base: experience with 30 cases. Skull base Surg 1:226-234, 1991

32. Spetzler RF, Daspit CP, Pappas CTE: The combined supra- and infratentorial approach for lesions of the petrous and clival regions: experience with 46 cases. J Neurosurg 76:588-599, 1992

33. Sugita K, Kobayashi S, Takemae T, et al: Aneurysms of the basilar artery trunk. J Neurosurg 66:500-505, 1987

34. Wissinger JP, Danoff D, Wisiol ES, et al: Repair of an aneurysm of the basilar artery by a transclival approach. Case report. J Neurosurg 26:417-419, 1967 
Manuscript received September 14, 1995.

Accepted in final form March 27, 1996.

This paper was presented in part at the 1995 annual meeting of the American Association of Neurological Surgeons, Orlando, Florida.

Address reprint requests to: Volker Seifert, M.D., Neurochirurgische Klinik, Universität-GHS-Essen, Hufelandstrasse 55, 45122 Essen, Germany. 